\title{
Saga of the Chemical Microscope
}

Walter $\mathrm{C}$. McCrone, McCrone Research Institute

The precursor of today's light microscope was invented probably in the Netherlands about 1600 . In effect it previously involved a two lens system - objective and the eyepiece. As such it was termed a compound microscope. It differed from the simple one-lens microscope of Anthony Leeuwenhoek in the 1600 's. The image was so bad, however, that most microscopists preferred to use the simple one-lens microscope. Leeuwenhoek, with his one-lens microscope, magnifying up to $280 \mathrm{X}$, discovered foraminifera and many other "wee beasties", even bacteria and spermatozoa.

The first major improvement to the microscope came about 1830 when John Dolland produced achromatic lenses that made the compound light microscope far superior to even the $280 \mathrm{X}$ simple microscope of Leeuwenhoek. About the same time, William Nicol invented the calcite polarizing prism. This produced an instrument of great value to chemists as a microanalytical tool. During the balance of the 19th century, toxicologists and, especially, forensic investigators adopted the polarized light microscope as their principal investigative tool. Analytical chemists soon also recognized its value for identifying unknown substances and for studying chemical problems. Henry Sorby was one of the first such chemists, and by 1896 Emile Chamot was teaching a chemical microscopy course at Cornell University. Other universities soon joined the trend and began their own courses. Many Chemistry departments required such courses for their B.S. degrees. Most industrial laboratories incorporated microscopy and microscopists in their research laboratories.

Starting early in the 20th century we see the invention of other physical analytical methods that, for a variety of reasons, soon became popular and began to replace microscopy. X-ray diffraction about 1910; emission spectroscopy about 1920; transmission electron microscopy about 1930; infrared absorption about 1940; plus scanning electron microscopy, electron microprobes and $x$-ray fluorescence during the 50's and 60's soon convinced the scientific world that the light microscope had outlined its usefulness.

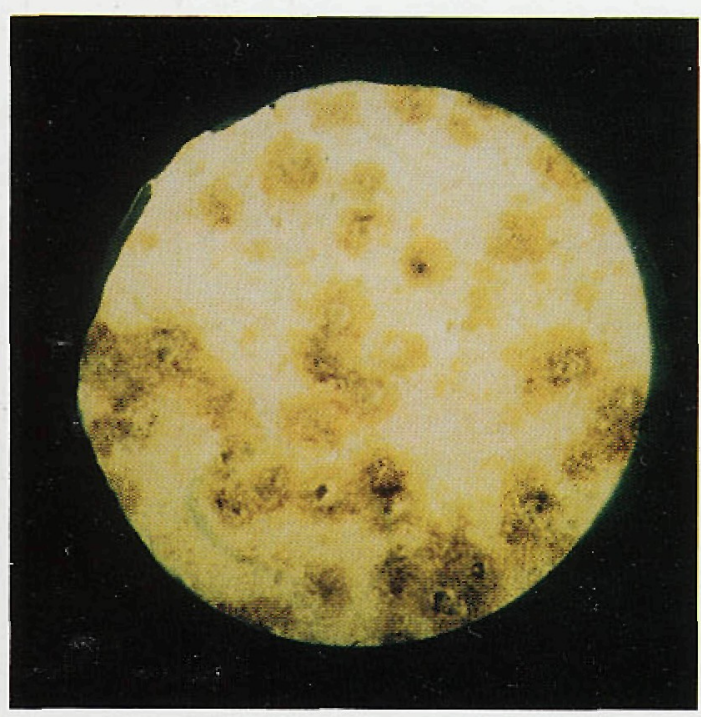

FIGURE 1

The spots on this drug tablet are brownish-red. This indicates a serious shelf-life problem: incompatibility of the components
The universities gave up teaching chemical microscopy (even Cornell by 1980) and those of us who stuck to that venerable tool were subjected to criticism or ignored. I am not alone in believing, however, that dropping the use of polarized light microscopy $(P L M)$ in the chemical laboratory is a great mistake. I have continued to use PLM to solve a variety of important problems like the identification of asbestos in all of its forms, studying the polymorphic forms of pharmaceuticals and explosives, and, less important, the fakery of the Vinland Map and the Turin Shroud. Partly because of my unpopular debunking of both the Map (VM) and the Turin Shroud, I have experienced considerable difficulty convincing today's scientists that the light microscope is still a valuable analytical tool. Dr. Harry Gove, a strong supporter of the more recent high-tech instruments, states in his recent book "Relic, Icon or Hoax?" "the trouble with McCrone is that his scientific techniques (PLM) are unsophisticated compared to AMS and PIXIE." Dr. Gove developed the Accelerator Mass Spectrometer (AMS) that was used to date the Shroud to the fourteenth century. Dr. Thomas Cahill of the University of Calilfornia (Davis) used PIXIE (Photon-Induced X-ray Emitter) to "prove" the Vinland Map is most likely authentic. Dr. Gove admits the Shroud is Medieval but only because his AMS dated it to $1325 \pm 65$ years. I am certain that both the VM and the Shroud will eventually be accepted as fakes just as PLM proved both to be. ${ }^{1,2}$

The result of this attitude toward PLM and the absence of courses in chemical microscopy (another name for PLM) is the widespread conviction that chemists should use XRD, FTIR, TEM, SEM, SEM/EDX, NMR, GC/MS, and ETC to solve chemical problems. I use PLM instead and I solve problems quickly and confidently but I then include confirmation data from McCrone Associates who have, in addition to PLM, all of the above acronyms and more. The latter then convinces my client, or readers of my published paper, that I was correct.

So, let me detail the changes in PLM since 1980 and suggest who and what could reverse the situation. The records of the McCrone Research Institute (MCRI) are an excellent source of the changes that have occurred since 1980. Worst of all, is the drop in enrollment at McRl: from 1589 (1989) to 485 (1999) a nearly $70 \%$ drop. The number of papers delivered at Inter/Micro (IM) meet-

\section{Continued on page 16}

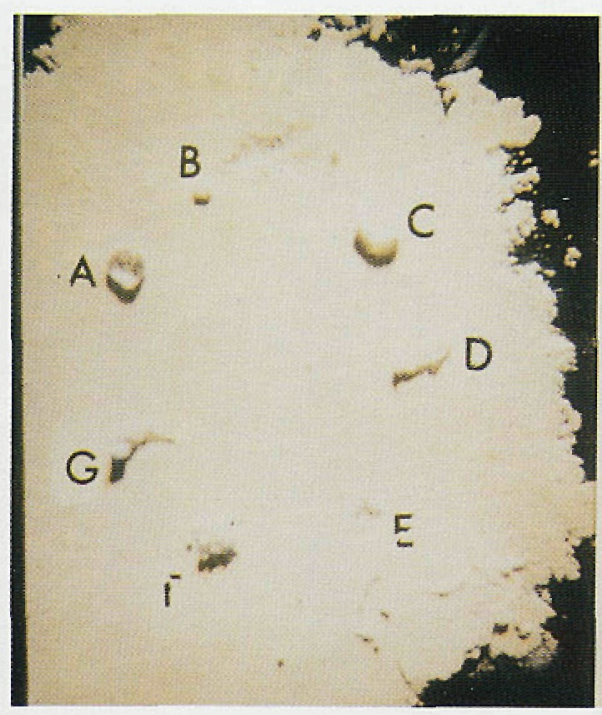

FIGURE 2A

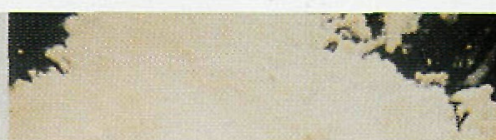

B

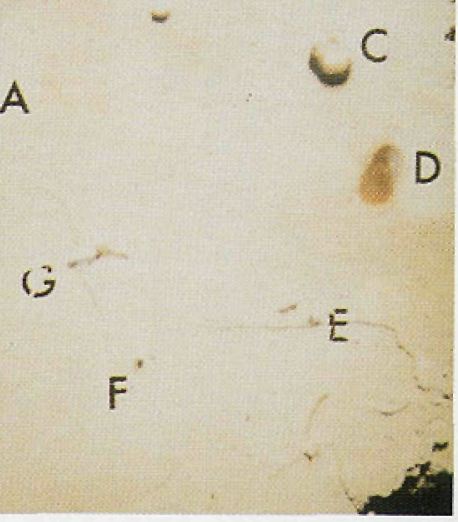

FIGURE $2 B$

$2 A$ shows a thin layer of powdered drug on which tiny known samples of the other components of the tablet have been placed. $2 \mathrm{~B}$ shows, after heating 5 minutes at $80^{\circ} \mathrm{C}$ in a microscope hot stage, a brownish-red spot where $D$, the excipient (oxalic acid) was placed. 


\section{6-D Imaging}

You've Got to See This

www.image1.com

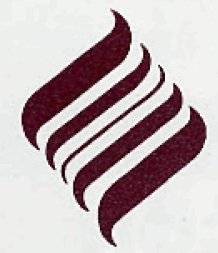

Universal Imaging Corporation ${ }^{\circledast}$ 
Saga of the Chemical Microscope Continued from page 14

ings decreased from 62 (1989) to 43 (1999), a 31\% decline. Now, for the punch-line, of the 43 papers delivered at IM- 89 only 13 have been published, 30 or $70 \%$ of those papers have not been published.

The net result of these disastrous decreases is the fact that few Lab Directors or Research Directors have ever used the polarized light microscope. They see only the age of the PLM and the availability of XRD, TEM, SAED, SEM, EDS, NMR, ES, MS, ESCA, Raman, IR, FTIR, DNA, etc. These highly sophisticated, automated, computer-controlled, and expensive instruments must be better than the venerable PLM. Yet, those of us who are lucky enough to be able to still use PLM know we can quickly and correctly solve forensic or, more generally, chemical product and process problems ${ }^{1-3}$ that, if solvable by the hi-tech acronyms, would take far more time and money. I will give just one example of the direct problem-solving approach a microscopist takes to solve a vexing chemical problem. Figure 1 shows a drug tablet mottled with brown spots indicating incompatibility of some of the components that occurred during normal shelf-life storage. The microscopist took one look and thought that one of the excipients in these tablets had reacted with another component, very probably the drug itself. So, he pressed some of the powdered drug on a microscope slide and added on top of the powder layer (Figure 2a) single particles or droplets of each of the excipients (obtained from the drug company that submitted the problem). The slide was then placed in a microscope hot stage and heated to $80^{\circ} \mathrm{C}$ for 5 minutes; the result is shown in Figure 2b. Obviously, Component $D$, known to be oxalic acid, was the cause of the brown spots. The use of PLM is a direct approach to problem solving and its answers are "yes" or "no" with $100 \%$ certainty. Still, the use of PLM techniques like microcrystal tests and optical crystallography are being increasingly ignored in forensic and other laboratories ${ }^{1}$.

This is a desperate situation. What can we do? The answer is that each of "us" must publish and lecture on examples of PLM success. We have been very lax in this respect. I admit my own sinful past and during the past year or so I've published half a dozen papers covering unpublished work done from 20 to 60 years ago ${ }^{2-7}$. I've also added a second week of American Chemical Society lecture tours to local sections scattered throughout the 50 states. It's up to all of "us" to concentrate on lectures and publications. After all, it's our job we're fighting for. I now understand what I've heard for years at universities: "Publish or Perish".

1. McCrone, Walter C. "The Vinland Map" Anal. Chem. (1988) 160 1004-1018.

2. McCrone, Walter C. "The Shroud of Turin, Blood or Artists Pigments", (1990) 23, 77-83.

3. Evans, Hiram H. "Drug and Microcrystal Tests for Forensic Drug Identification, Microscope (1999) 47:3, p. 147

4. McCrone, Walter C., "Choosing Proper Chemical Problem-Solving Instrumentation" American Laboratory (October 1998) pp. 27-34.

5. McCrone, Walter C. "Attention Laboratory Directors", American Laboratory (April 1999) pp. 37-44.

6-8 McCrone, Walter C. "Identification of Organic High Explosives" I-III, Microscope (1993) 41:3, 161-182 (I); (1944) 42:2, 61-72 (II); and (1999) 47, $183-200$ (III).

9. McCrone, Walter C. and Michael A. Bayard "Individualization of Hair" Microscope (1999) 473 pp. 129-134.

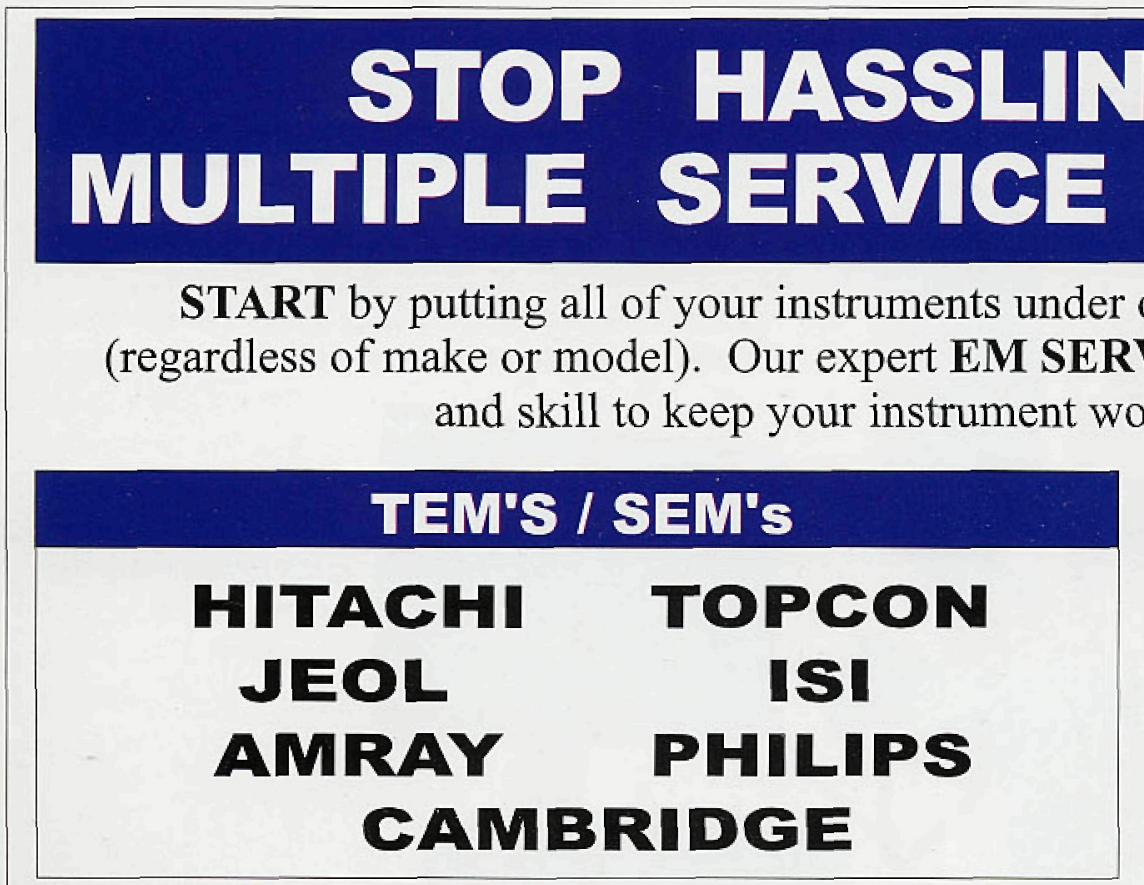

WE SERVICE

COMPUTER CONTROLLERS

BEAM BLANKERS

WATER CHILLERS
Contracts and On-Demand Emergency Service at Reasonable Rates from Factory Trained Specialists.

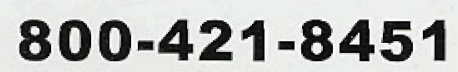

PREP EQUIPMENT

VACUUM COATERS MECHANICAL PUMPS TURBO PUMPS PLASMA ASHERS SPUTTER COATERS

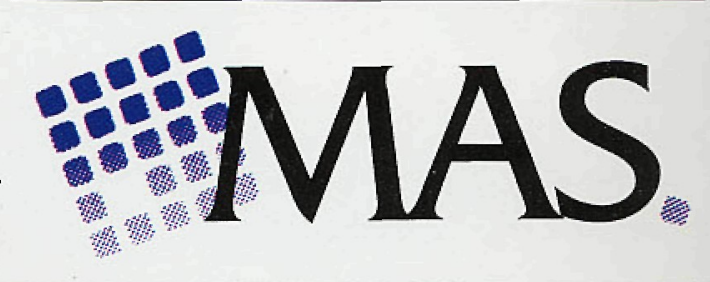

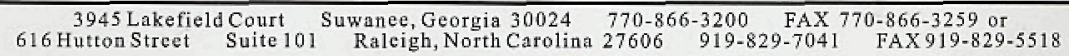
ADVANCED ANALYTICAL PRODUCTS AND SERVICES 